\section{Gategory}

Metal-Catalyzed Asymmetric Synthesis and Stereoselective Reactions

\section{Key words}

asymmetric catalysis

hydroamination

alkenes

amines

copper

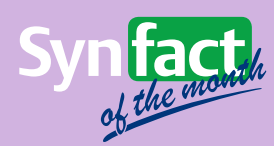

Y. YANG, S.-L. SHI, D. NIU, P. LIU, S. L. BUCHWALD* (MASSACHUSETTS INSTITUTE OF TECHNOLOGY, CAMBRIDGE AND UNIVERSITY OF PITTSBURGH, USA)

Catalytic Asymmetric Hydroamination of Unactivated Internal Olefins to Aliphatic Amines Science 2015, 349, 62-66.

\title{
Enantioselective Hydroamination of Unactivated Internal Olefins
}

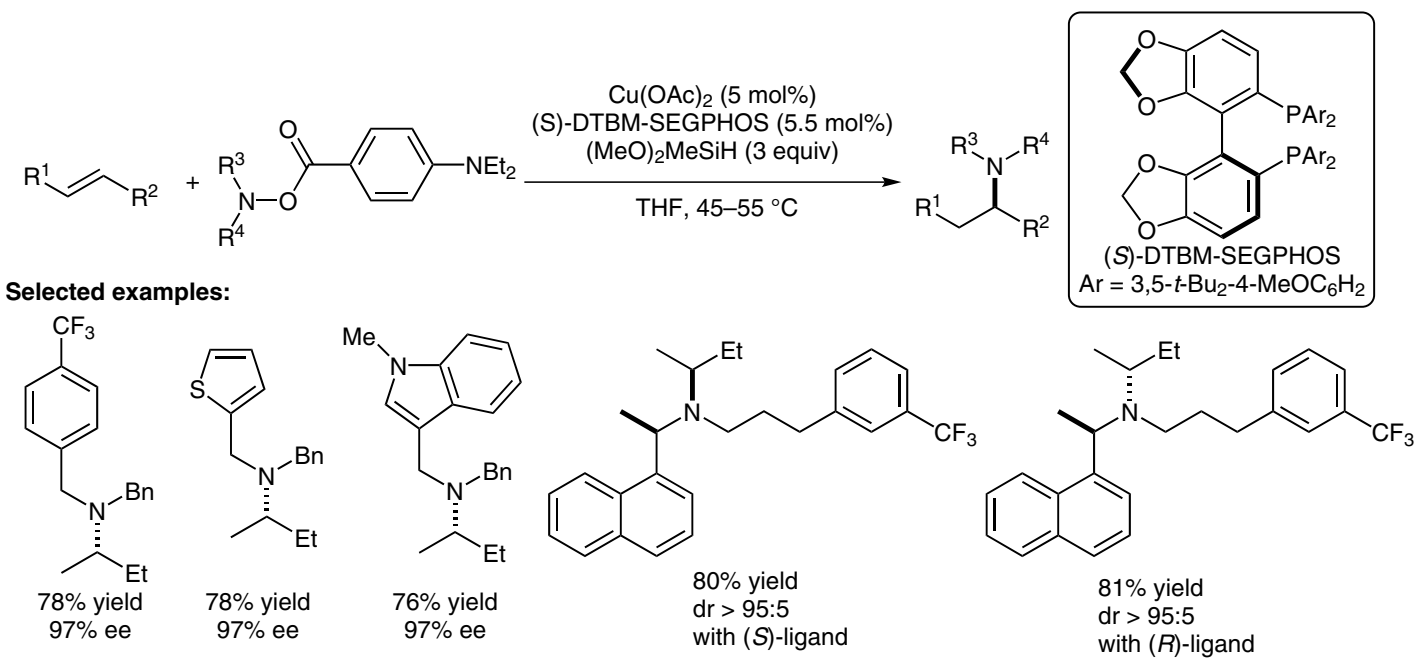

Proposed reaction mechanism:<smiles>CC(C)CCCCCC(=O)O[SiH3]</smiles>

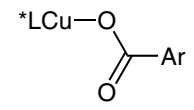

Significance: Previous hydroaminations of alkenes have been achieved with a restricted range of substrates (for example, styrenes or terminal olefins). Here, the authors succeed in asymmetric hydroamination of nonactivated internal olefins. This system provides ready access to various $\alpha$-branched chiral amines with high enantioselectivities ( $\geq 96 \%$ ee).

SYNFACTS Contributors: Hisashi Yamamoto, Yasushi Shimoda Synfacts 2015, 11(9), 0946 Published online: 18.08.2015 DOI: 10.1055/s-0035-1560099; Reg-No.: H09815SF
Comment: Electron-rich hydroxylamines are used as aminating reagent to suppress undesired reductions of hydroxylamines. The late-stage modification of pharmaceutical compounds is also demonstrated. 